(8)

\title{
Vaporization kinetic study of lavender and sage essential oils.
}

\author{
Celia Duce ${ }^{1}$, Stefano Vecchio Ciprioti ${ }^{2, *}$, Alessio Spepi ${ }^{1}$, Luca Bernazzani ${ }^{1}$, Maria Rosaria Tinè ${ }^{1}$ \\ ${ }^{1}$ Dipartimento di Chimica e Chimica Industriale, Università di Pisa, \\ Via G. Moruzzi 13, I-56124 Pisa, Italy \\ ${ }^{2}$ Dipartimento di Scienze di Base ed Applicate per l'Ingegneria, Sapienza Università di Roma, \\ Via del Castro Laurenziano 7, I-00161 Roma, Italy
}

\begin{abstract}
The thermal behavior of lavender and sage essential oils (EOs) and also that of their main components (camphor and 1,8-cineole) were studied by thermogravimetry (TG) at different scan rates under inert gas atmosphere up to about $140{ }^{\circ} \mathrm{C}$. All the samples investigated undergo a single-step evaporation starting from ambient temperature without evidence of side decomposition processes. On the basis of the onset temperatures $\left(T_{\mathrm{on}}\right)$ extrapolated from the TG curves the following increasing stability trend is assessed:
\end{abstract}

However, the difference of $T_{\text {on }}$ values among the first three samples was found to be slight. To the aim of assessing a thermal stability scale among the samples, a kinetic analysis of evaporation was performed. A first approach was based on a simple model-fitting kinetic method, widely used in the past for studying evaporation of EOs. The results were compared with those obtained with a more reliable approach based on the integral isoconversional method by Kissinger-Akahira-Sunose in which the activation energy (E a) versus reaction extent $(\alpha)$ plot of each sample was obtained. Because of the compensation effect, neither activation energy nor the pre-exponential factor, alone, could be considered to compare the stabilities. Lastly, the Arrhenius kinetic rate constant values at given temperatures within the experimental range were calculated, and camphor was found to be the more stable component, while lavender seems to vaporize faster than any other sample tested.

Keywords Essential oils, Lavender, Sage, 1,8-cineole, camphor, TG, Modulated TG, Vaporization kinetics, Kissinger-Akahira-Sunose method

\footnotetext{
${ }^{*}$ Corresponding Author:

(S. Vecchio Ciprioti) E-mail Address: stefano.vecchio@uniroma1.it
} 


\section{Introduction}

Essential oils (EOs), also called volatile or ethereal oils, are hydrophobic liquids containing volatile compounds obtained from plant material (flowers, buds, seeds, leaves, twigs, bark, herbs, wood, fruits and roots) that have gained great popularity as alternatives for artificial additives or pharmacologically relevant agents in food, cosmetic and pharmaceutical industries or simply as flavoring material.

Sage and lavender are spontaneous herbs belonging to the Lamiaceae family and their EOs, whose composition includes in both cases camphor and 1,8-cineole as principal components, show important properties. In particular, sage possesses well-recognized biological activity as antibacterial, antioxidant [1] and anti-inflammatory agent [2], and lavender exhibits antioxidant activity in conservation of food [3] and pharmaceutical properties, as anticonvulsive [4], antidepressant [5], antiviral [6], antibacterial [3] and antifungal [7, 8].

Although the use of EOs dates back to $4500 \mathrm{BC}$, it is specially from the Middle Ages that they have become common in the everyday life, due to the development by the Arabs of the steam (SD) or hydro-distillation (HD) techniques, which still remain the main methods of extraction of EOs.

During the last years, EOs have expanded their applications in specific fields as therapeutic agents in biomedicals [9] or in new applications in nanotechnology or synthesis [10], justifying the efforts to develop efficient and low-cost methodologies to isolate these valuable renewable products from different herbs. In this respect, it is noteworthy that the yield, extraction time and chemical composition of EOs are influenced not only by parameters like growing environmental conditions, genetic variety and organ of the plant sample, but also by the extraction approach used to their isolation.

Novel extraction techniques, namely "green extractions," have been developed in order to maximize the yield percent, while the time processing and energy demand are reduced. The success of these approaches is based on their capability to produce EOs with the same quality and sensorial properties as those obtained by the conventional techniques but in a faster and cheaper way. In this respect, 
microwave (MW)-assisted extraction technology can be considered a convenient methodology to obtain essential oils from several herbs $[11,12,13,14,15,16]$.

Currently, lavender and sage EOs are primarily produced from leaves and flowers by conventional extraction methods, namely HD and SD [17]. Although the distillation techniques are both, simple and low cost, there are severe limitations in their use because of thermolability of compounds (high operating temperature), hydrolysis of water-sensitive compounds (prolonged extraction time) and incomplete extraction.

To the aim to overwhelm these limitations, our innovative MW-assisted HD method, where the electromagnetic energy is applied directly inside the aqueous medium by a coaxial dipole antenna, was successfully applied to extraction of EOs from sage and lavender [14].

At the same time, we realized that, in order to furnish a rational base to the prevention of the bioactivity of sage and lavender EOs, of their characteristic aromatic properties, and to validate the efficiency of our extraction method, the thermal stability and the rate of volatilization of EOs and of their principal pure components should be carefully investigated.

As a matter of fact, although the vapor pressure is the fundamental quantity determining the volatility of a pure compound [18], in the case of a complex mixture of volatiles, such as EOs [19], the vapor composition at equilibrium also reflects the molecular interactions determining, in turn, the activity coefficients of each component. Moreover, the vaporization of a volatile mixture can occur in nonequilibrium conditions giving rise to a situation, even more difficult to predict, where the volatility of each component is affected by the corresponding evaporation rate [20]. Finally, degradation (pyrolytic or oxidative) of one or more components can also occur. Each of the above-mentioned aspects proves crucial in ruling the prevention of original properties of EOs and for their safe and proper handling during product formulation.

Many studies have been performed in the past, aimed to the determination of the evaporation rate at ambient temperature or slightly higher. For instance, Rudolfi and co-worker developed a rapid 
method for determining the evaporation rate of EOs using a conventional gas chromatographic technique [20].

In the recent past, we successfully used thermal analysis techniques to investigate the drying oils with particular reference to their drying, polymerization and oxidative degradation [21, 22] and EOs' thermal stabilities [14]. However, in the literature few studies report a comprehensive analysis of thermal behavior, vaporization characteristic and stability of EOs $[23,24,25,26]$. Hazra et al. [23, 24] dealt with the vaporization kinetics of different EOs and their main components by carrying out single thermogravimetric experiment (TG) at a single heating rate, assuming a zero-order reaction by simply observing the profiles of the corresponding derivative curves (DTG) and by using a model-fitting approach. However, the reliability of this approach was found questionable by valuable members of the Kinetic Committee of the International Confederation of Thermal Analysis and Calorimetry (ICTAC) in several papers and reviews published in 2000 [27], 2011 [28] and 2014 [29].

In this study, the thermal behavior of lavender and sage EOs and of their main components (camphor and 1,8-cineole) were investigated by TG at different heating rates, similarly to what has been made in the past with commercial vegetable oils by Dweck and Sampaio [30]. Subsequently, aiming at assessing a thermal stability scale among this series of EOs and related components a kinetic analysis of evaporation was performed. To this purpose, we decided first to check the reliability of a simple model-fitting method (as made in the past $[23,24]$ ) and compare the results with those obtained with a more reliable approach based on the integral isoconversional method by Kissinger-Akahira-Sunose (KAS) [31, 32]. This approach was successfully applied to the vaporization kinetics of the pesticides such as alachlor and metolachlor whose activation energy was found substantially constant over the whole range of the extent of reaction, $\alpha$ [33]. After the kinetic analysis of evaporation of the four samples (lavender, sage, 1,8-cineole and camphor) was performed and the corresponding stability scale was assessed, a comparison with that based on the extrapolated onset temperature was made. 


\section{Theoretical background of Kinetic Analysis}

110 Substances in the condensed phase (like EOs or EOs components) may undergo vaporization with or

111 without decomposition, and the reaction rate can be monitored as a function of temperature (from 112 non-isothermal and constant heating rate, $\beta=\mathrm{d} T / \mathrm{d} t$, TG experiments) through the change in the extent 113 of reaction, defined as $\alpha=\left(m_{0}-m_{\mathrm{T}}\right) /\left(m_{0}-m_{\mathrm{f}}\right)$, where $m_{0}, m_{\mathrm{T}}$ and $m_{\mathrm{f}}$ are the initial sample mass, the 114 sample mass at a given temperature and the sample mass at the end of a reaction, respectively. The 115 kinetic approach starts by assuming that the general equation describing the rate of a reaction 116 involving a substance in the condensate state $\mathrm{d} \alpha / \mathrm{d} t$ is a function of both the two variables $T$ and $\alpha$ :

$$
\mathrm{d} \alpha / \mathrm{d} t=k(T) f(\alpha)
$$

where the $k(T)$ temperature function often has the meaning of the Arrhenius specific rate constant and $f(\alpha)$ is the so-called differential model function, whose mathematical expressions representing the reaction mechanisms are available from literature $[29,34,35]$. For a non-isothermal TG experiment under constant heating rate, using the Arrhenius equation for the temperature dependence of $k(T)$, it 122 yields:

$$
\mathrm{d} \alpha / \mathrm{d} t=(\mathrm{d} \alpha / \mathrm{d} T) \beta=A \exp \left(-E_{\mathrm{a}} / R T\right) f(\alpha)
$$

where $A$ and $E_{\mathrm{a}}$ are the pre-exponential factor and the activation energy, respectively, and along with the selected $f(\alpha)$ are sometimes called the kinetic triplet. Rearranging Eq. (2) with the view to separate the two variables $T$ and $\alpha$, and considering that $g(\alpha)=\int \mathrm{d} \alpha / f(\alpha)$ :

$$
g(\alpha)=(A / \beta) \int_{0}^{T} \exp \left(-E_{\mathrm{a}} / R T\right) \mathrm{d} T=\left(A E_{\mathrm{a}} / R \beta\right) \int_{x}^{\infty} \exp (-x) / x^{2} \mathrm{~d} x=\left(A E_{\mathrm{a}} / R \beta\right) p(x)
$$

where $g(\alpha)$ is called the integral model function and $x=E_{\mathrm{a}} / R T$, and the integration limits were correspondingly transformed. Since the temperature integral $p(x)$ in Eq. (3) has no exact mathematical solution it is often replaced by approximations, one of the most common being the asymptotic series 131 expansion considered in the Coats-Redfern (CR) model-fitting method [36, 37], represented by the following Eq. (4):

$$
\ln \left[g(\alpha) / T^{2}\right]=\ln \left\{\left(A R / \beta E_{\mathrm{a}}\right)\left[1-\left(2 R\langle T\rangle / E_{\mathrm{a}}\right)\right]\right\}-E_{\mathrm{a}} / R T,
$$


134 where $\langle T\rangle$ is the average of the experimental temperature range. From the intercept and slope of the

135 linear regression obtained by plotting the left hand side of Eq.(4) against the reciprocal absolute 136 temperature the corresponding $A$ and $E_{\text {a }}$ have been determined, respectively. The most suitable model 137 function(s) can be selected on the bases of the best linear fit of Eq. (4). Once the so-called kinetic 138 triplet is determined using this model-fitting method, the $\alpha$ vs. $T$ curve can be reconstructed starting 139 from $\alpha_{0}$ (equal to 0.025 in this study) and using as differential increments of $\alpha$ the expression obtained rearranging Eq. (2):

$$
\mathrm{d} \alpha_{\mathrm{j}}=A_{\mathrm{j}} / \beta \exp \left(-E_{\mathrm{a}, \mathrm{j}} / R T\right) f_{\mathrm{j}}(\alpha) \mathrm{d} T
$$

where the subscript $\mathrm{j}$ refers to the mechanism selected according to the procedure previously described. A good agreement between the experimental and reconstructed $\alpha$ vs. $T$ curves should confirm the reliability of the approach used. By contrast, model-free methods that use TG data obtained from experiments performed under different heating rates were found to provide more reliable results. Among them one of the most popular is the integral isoconversional method firstly proposed by Kissinger-Akahira-Sunose [30], based on the following equation:

$$
\ln \left(\beta / T_{\alpha}^{2}\right)=\text { Const }-E_{\alpha} / R T_{\alpha}
$$

At each given value of $\alpha$, a single value of activation energy can be calculated from the slope of the regression line obtained by plotting the left hand side of Eq. (6) against the reciprocal isoconversional temperature $\left(T_{\alpha}\right)$. By applying the CR model-fitting method a pair of $A$ and $E_{\text {a values can be obtained }}$ for each reaction model using a single-heating rate experiment. Wide ranges of pair values were usually found when all the usual reaction models were considered, and a strong linear correlation (called compensation effect) is found between them in the following form:

$$
\ln A_{i}=a E_{i}+b
$$

where the subscript $\mathrm{i}$ refers to each of all the reaction model. Once $a$ and $b$ parameters have been determined at each heating rate using a linear regression procedure, these values were replaced in Eq. (7) by the $\langle a\rangle$ and $\langle b\rangle$ values, as averages of the pair values obtained in the five replicates (one for 
each TG experiment at a given value of $\beta$ ). Then, the $E_{\mathrm{i}}$ values were replaced by the isoconversional $E_{\alpha}$ values in order to determine the corresponding $\ln A_{\alpha}$ values at each given value of $\alpha$ [38].

\section{Experimental}

163

164

\section{Materials}

The leaves and stems of fresh lavender and sage plants were collected in October 2014 from a courtyard located in the city of Pisa, (Tuscany, Italy). These raw plant materials were harvested daily during the experimental period and used as substrate to obtain their EO. Deionized water obtained with a Milli-Q system (Millipore, Bedford, MA, USA) was used as solvent for the EO extraction.

\section{Instruments}

The TG/DTG experiments were carried out using a TA Instruments Thermobalance model Q5000IR. TG measurements were performed from about 25 to $150{ }^{\circ} \mathrm{C}$ under inert flowing nitrogen atmosphere $\left(25 \mathrm{~mL} \mathrm{~min}^{-1}\right)$ using Pt crucibles. Five TG experiments at different heating rates $(2,4,6,8$ and $10 \mathrm{~K}$ $\min ^{-1}$ ) were performed for each sample, being the experiment at $2 \mathrm{~K} \mathrm{~min}^{-1}$ that used to study the thermal behaviour. Mass calibration was performed using certified mass standards, in the range from 0 to $100 \mathrm{mg}$, supplied by TA Instruments. The amount of sample in each measurement varied between 1.2 and $1.5 \mathrm{mg}$. Temperature calibration was based on the Curie point of paramagnetic metals. A multipoint calibration with five Curie points from reference materials (Alumel, Ni, Ni83\%Co17\%, Ni63\%Co37\%, Ni37\%Co63\%) was performed.

\section{Results and discussion}

The EOs were analyzed by gas chromatography (GC-FID) and gas chromatography-mass spectrometry (GC-MS) techniques in a previous work [14] and their compositions are shown in Fig. 1. 
183 The TG/DTG curves of the oily samples of lavender, sage, 1,8-cineole and camphor carried out at 2

$184 \mathrm{~K} \mathrm{~min}^{-1}$ under a nitrogen flow are displayed in Fig. 2. All the samples undergo only one step of mass

185 loss starting from ambient temperature without appreciable differences among them, except for

186 lavender, for which two distinguished and consecutive steps of mass loss are found. In order to better

187 study these processes, the peaks of reaction rate, d $\alpha / \mathrm{dT}$, were deconvoluted (Fig. 3) using two

188 Gaussian peaks exponentially modified to make them asymmetrical. A multiparameter least-square

189 approach was used to determine the best fit between the models (in blue and red in Fig. $3 \mathrm{~b}$ for the

190 first and the second peaks, respectively). The first one, who involves about $80 \%$ of the mass loss from

191 ambient temperature to $75.6^{\circ} \mathrm{C}$, was studied in detail from a kinetic point of view, and the results

192 obtained were compared with those deriving from the single step of the others. So, after the TG data

193 have been collected at all heating rates (from 2 to $10 \mathrm{~K} \mathrm{~min}^{-1}$ ) the extrapolated onset vaporization

194 temperatures $\left(T_{\text {on }}\right)$ were determined with the aim to find a parameter able to assess a stability scale

195 among the samples tested. The plot of the T on values as a function of heating rate $(\beta)$ is given in Fig.

1964 along with the regression (dotted) lines. The value for lavender is referred to the first step, even if

197 no difference is found (within the estimated temperature uncertainties) with the value obtained using

198 the TG portion related to the first step only. As it can be seen, extrapolation of these values at null

199 heating rate provides similar values around $30{ }^{\circ} \mathrm{C}$ for sage, lavender and 1,8-cineole, while only the

200 value of camphor is higher than $40^{\circ} \mathrm{C}$, thus suggesting that this could be the more stable among the

201 oily samples investigated. However, this result could be misinterpreted since it is mainly due to the 202 difference in the shapes of their TG curves, with particular reference to its slowest initial mass loss 203 with respect to those of the other three samples (Fig. 2): Camphor loses $20 \%$ of its mass in a 204 temperature range of about $20-25^{\circ} \mathrm{C}$, while the other three give the same result in only $5-7^{\circ} \mathrm{C}$. On 205 the other hand, looking carefully at the slopes of the linear portion of the TG curves around the 206 inflection point, that of 1,8-cineole is more negative than those of lavender and sage which, in turn, 207 is similar to that of its main component camphor (see Fig. 2). Since the slopes are expected to be 
proportional to the rates of vaporization, the above observation suggests that 1,8 -cineole vaporizes 209 faster than the other samples.

210 In any case, the thermal behaviour study of these samples must be considered preliminary, but not 211 sufficient to provide exhaustive information on their stabilities. So, we carried out a kinetic analysis 212 of vaporization of these samples, starting with a model-fitting approach very similar to that already 213 applied in the past $[23,24]$. To this purpose, the CR method, based on processing data from a single 214 TG run according to Eq. (4), was considered. Four best model functions were selected for 215 vaporization of all samples on the basis of the best linear fit (the highest values of $R^{2}$, squares of the 216 correlation coefficients) and reported in Table 1 along with the Arrhenius parameters $\left(E_{\mathrm{a}}\right.$ and $\left.A\right)$. The 217 first set of data were determined from $\mathrm{TG}$ experiments performed at $2 \mathrm{~K} \mathrm{~min}^{-1}$, while a second set of 218 data were obtained from TG runs carried out at $10 \mathrm{~K} \mathrm{~min}^{-1}$, with the view to verify possible 219 interferences of the heating rate. The same four models were selected for the vaporization of the four samples regardless of the heating rate considered. Moreover, no significant differences can be attributed to the four $R^{2}$ values, thus concluding that the four models should be considered equivalent, even though the pair values associated to each model were found, especially in some cases, remarkably different. In order to find the most suitable models, a reconstruction of the $\alpha$ vs. $T$ curves was made, according to Eq. (5), and compared to the experimental one (Fig. 5) at the lowest and highest heating rates considered. All the reconstructed curves fit quite well with the experimental ones in a significant range of extent of conversion, except for the case of sage according to model D3 (plots c, d), showing a remarkable deviation from the corresponding experimental curves. This behavior does not allow to univocally select the most suitable model, thus indicating that this approach fails to provide a thermal stability scale among the investigate EOs (Table 2).

A comparison with the literature was only possible for lavender EO whose evaporation was found to reach $50 \%$ at $76{ }^{\circ} \mathrm{C}$ (constant temperature) in $13 \mathrm{~min}$ [20]. In our study, this percentage of 232 vaporization was reached between 50 and $75^{\circ} \mathrm{C}$ depending on the heating rate used $\left(2\right.$ and $10 \mathrm{~K} \mathrm{~min}{ }^{-1}$ in Fig. 5a, b plots, respectively). 
Dollimore and co-worker claimed that evaporation of 1,8-cineole, lavender and other 11 EOs is a "non-activated zero-order" process. However, they simply derived this result by observing the closeness of vaporization enthalpies from Clausius-Clapeyron equation with the activation energy obtained by assuming a zero-order reaction $[23,24]$. Our approach, though inadequate to find a reasonable model function for vaporization of the investigated samples, disagrees with the zero-order reaction assumption. Incidentally [24], these authors also claim that their method could furnish the vapor pressure curve for multicomponent systems, provided that the exact composition or the average molecular weight is known. In our opinion, this conclusion is very questionable since activity coefficients (unknown) may strongly affect the properties of the mixture.

The $E_{\text {a versus }} \alpha$ dependencies for vaporization of lavender (limited to the first step only), sage, 1,8cineole and camphor calculated according to KAS are displayed in Fig. 6, where the relative uncertainties associated with the E $\alpha$ values (RUE, \%), expressed as error bars, were estimated to be always lower than $8 \%$. The $E_{\mathrm{a}}$ versus $\alpha$ curves show a decreasing trend, typical of the reversible processes [35], similarly to what previously observed for dehydration of different materials $[39,40,41,42]$. The results substantially confirm the stability order inferred on the basis of the $T_{\text {on, }}$, since the higher is the energy barrier (for vaporization of camphor), the slower is the vaporization rate, while 1,8-cineole and sage seem to have the highest (and comparable) reaction rates. On the other hand, these results match the thermochemical data related to phase transition for both camphor and 1,8-cineole [43]. In fact, the higher volatility of 1,8-cineole with respect to camphor could be expected on the basis of its lower boiling temperature (449.5 against $482.3 \mathrm{~K}$ ) or its lower standard molar enthalpy of vaporization at $298.15 \mathrm{~K}\left(49.0\right.$ or 53.2 against $\left.54.5 \mathrm{~kJ} \mathrm{~mol}^{-1}\right)$.

However, the thermal stability (or volatility) cannot be assessed only on the basis of the activation energy. Actually, it is commonly found that $\mathrm{E}$ a obtained using a model-fitting method is not independent of pre-exponential factor, but the two quantities are strictly correlated through the compensation effect previously described in Eq. (6). To confirm this, the natural logarithm of A $\alpha$ is plotted versus the extent of conversion (Fig. 7) showing the same trends of Fig. 7. 
Lastly, in order to have a clearer idea of the stability order, kinetic rate constants $k_{\text {vap }}\left(\langle T\rangle_{\alpha, \beta}\right)$ were 261 calculated according to the well-known Arrhenius equation, at the temperatures $\langle T\rangle_{\alpha, \beta}$ [average 262 between $T(\alpha=0.2)$ and $T(\alpha=0.8)$ at a given heating rate $\beta]$. These values are summarized in Table 2633 for vaporization of all four samples. The $k_{\text {vap }}\left(\langle T\rangle_{\alpha, \beta}\right)$ values show that camphor seems to be the 264 most stable, thus confirming the results of thermal behavior (the highest $T_{\mathrm{on}}$ ). Furthermore, lavender seems to vaporize faster than any other sample, while no significant difference are worth noting between the values referred to sage and 1,8-cineole, which can be considered to have comparable stability within the errors associated with these results.

\section{Conclusions}

271 Thermal behavior and vaporization kinetics of EOs was scarcely investigated in the past, and only 272 few data are available in literature on this topic. In addition, kinetic methods applied in this study 273 require a priori assumptions not supported by experimental evidence and are now out of date. An 274 early model-fitting method was used within this work only as preliminary approach for comparison purpose.

Our investigation involves the application of a modern kinetic approach to vaporization of essential oils (from thermogravimetric data) based on an integral isoconversional method, which meets the recommendations of the Kinetic Committee of ICTAC. In the case of lavender, where two-step vaporization occurred, the first step was considered for the kinetic computations, and the results obtained were in accordance with those of vaporization for the other samples. It was possible to verify that the Arrhenius pair values (namely, activation energy and pre-exponential factor) do not vary appreciably with the extent of conversion (at least in the range between 0.20 and 0.80 ). The kinetic results based on the $k_{\mathrm{vap}}\left(\langle T\rangle_{\alpha, \beta}\right)$ values seem to confirm in some way the first preliminary observation 284 on the thermal behavior, thus revealing that camphor is the more stable among the samples examined. The stabilities of the other samples based on the thermal behavior (on $T_{\text {on }}$ reported in Fig. 4 ) seem to 
286 be comparable, thus revealing that in this case the TG is not able to discriminate among vaporization 287 of substances with similar volatility. On the other hand, slight differences have been observed taking 288 into account the $k_{\text {vap }}\left(\langle T\rangle_{\alpha, \beta}\right)$ values listed in Table 3. In particular, the following increasing order of 289 stability could be hypothesized for the three remaining samples: lavender $<1,8$-cineole $\leq$ sage. In any 290 case, lavender seems to vaporize faster than any other sample, while no significant difference is worth 291 noting between the values referred to sage and 1,8-cineole, which can be considered to have 292 comparable stability within the errors associated with these results. 


\section{Reference}

1. Boujaj S, Benyamna A, Bouamama H, Romane A, Falconieri D, Piras A, Marongiu B. Antibacterial, allelopathic and antioxidant activities of essential oil of Salvia officinalis L. growing wild in the Atlas Mountains of Morocco. Nat Prod Res. 2013;27(18):1673-6.

2. Tosun A, Khan S, Kim YS, Calìn-Sanchez A, Hysenaj X, Carbonell-Barrachina A. Essential oil composition and anti-inflammatory activity of Salvia officinalis L. (Lamiaceae) in murin macrophages. Trop J Pharm Res. 2014;13(6):937-42.

3. El Rhaffari L, Ismaili-Alaoui M, Belkamel J, Jeannout V. Chemical composition and antibacterial properties of the essential oil of Lavandula multifida L. Int J Essent Oil Ther. 2007;1:122-5.

4. Yamada K, Mimaki Y, Sashida Y. Anticonvulsive effects of inhaling lavender oil vapour. Biol Pharm Bull. 1994;17(2):359-60.

5. Ueno T, Matsui Y, Masuda H, Nishimura O, Togawa M, Sakuma K, Yokogoshi H. Antidepressant-like effects of 3-(3,4-dihydroxyphenyl)lactic acid isolated from lavender (Lavandula angustifolia) flowers in mice. Food Sci Technol Res. 2014;20:1213-9.

6. Kobeasy M, El Shazly MA, Rashed MM, Yousef RS. Antiviral action of lavender (Lavandula Vera) essential oil against tomato spotted wilt virus infected tomato plant. J Chem Acta. 2013;2(1):53-60.

7. D’Auria FD, Tecca M, Strippoli V, Salvatore G, Battinelli L, Mazzanti G. Antifungal activity of lavandula angustifolia essential oil against candida albicans yeast and mycelial form. Med Mycol. 2005;43(5):391-6.

8. Tullio V, Nostro A, Mandras N, Dugo P, Banche G, Cannatelli MA, Cuffini AM, Alonzi V, Carlone NA. Antifungal activity of essential oils against filamentous fungi determined by broth microdilution and vapour contact methods. J Appl Microbiol. 2007;102:1544-50.

9. Bilia AR, Guccione C, Isacchi B, Righeschi C, Firenzuoli F, Bergonzi MC. Essential oils loaded in nanosystems: a developing strategy for a successful therapeutic approach. Evid Based Complement Alternat Med. 2014;2014:651593-607.

10. Haleemkhan AA, Naseem B, Vardhini BV. Synthesis of nanoparticles from plant extracts. Int J Modern Chem Appl Sci. 2015;2(3):195-203.

11. Li Y, Fabiano-Tixier AS, Chemat F. Essential oils as reagents in green chemistry. Berlin: Springer; 2014. doi:10.1007/978-3-319-08449-7.

12. Flamini G, Cioni PL, Maccioni S, Baldini R. Composition of the essential oil of Daucus gingidium L. subsp. Gingidium. Food Chem. 2007;103:1237-40. 
13. González-Rivera J, Tovar-Rodríguez J, Bramanti E, Duce C, Longo I, Fratini E, GalindoEsquivel IR, Ferrari C. Surfactant recovery from mesoporous metal-modified materials (Sn-, Y, Ce-, Si-MCM-41), by ultrasound assisted ion-exchange extraction and its re-use for a microwave in situ cheap and eco-friendly MCM-41 synthesis. J Mater Chem A. 2014;2(19):7020-33.

14. Gonzalez-Rivera J, Duce C, Falconieri D, Ferrari C, Ghezzi L, Piras A, Tinè MR. Coaxial microwave assisted hydrodistillation of essential oils from five different herbs (lavender, rosemary, sage, fennel and clove buds): chemical composition and thermal analysis. Innov Food Sci Emerg Technol. 2016;18:2164-74.

15. Gonzàlez-Rivera J, Spepi A, Ferrari C, Duce C, Longo I, Falconieri D, Piras A, Tinè MR. Novel configurations for a citrus waste based biorefinery: from solventless to simultaneous ultrasound and microwave assisted extraction. Green Chem. 2016;18:6482-92.

16. Gonzàlez-Rivera J, Duce C, Ierardi V, Longo I, Spepi A, Tinè MR, Ferrari C. Fast and ecofriendly microwave assisted synthesis of silver nanoparticles using rosemary essential oil as renewable reducing agent. Chem Select. 2017;2:2131-8.

17. Schmidt E. Handbook of essential oils science technology and application. In: Baser GHC, Buchbauer K, editors. Handbook of essential oils science, technology, and applications. Boca Raton: Taylor and Francis Group, LLC; 2010.

18. Appel L. Physical foundations in perfumery. Part III. Vapor pressure. Am Perfum Cosmet. 1964;79:29-41.

19. Appel L. Physical foundations in perfumery. Part VI. Volatility of the essential oils. Am Perfum Cosmet. 1968;83(11):37-47.

20. Rudolfi TA, Shchedrina MM, Mindlin LO. Determination of the evaporation rate of essential oils and perfumery compositions using gas chromatography. Chromatographia. 1988;25(6):5202.

21. Bonaduce I, Carlyle L, Colombini MP, Ferrari C, Ribechini E, Tiné MR. A multi-analytical approach to studying binding media in oil paintings. Characterisation of differently pre-treated linseed oil by DE-MS, TG, and GC/MS. J Therm Anal Calorim. 2012;107:1055-66.

22. Duce C, Bernazzani L, Bramanti E, Spepi A, Colombini MP, Tiné MR. Alkyd artists’ paints: do pigments affect the stability of the resin? A TG and DSC study on fast-drying oil colours. Polym Degrad Stab. 2014;105:48-58.

23. Hazra A, Alexander K, Dollimore D, Riga A. Characterization of some essential oils and their key components: thermoanalytical techniques. J Therm Anal Calorim. 2004;75:317-30. 
24. Hazra A, Dollimore D, Alexander K. Thermal analysis of the evaporation of compounds used in aromatherapy using thermogravimetry. Thermochim Acta. 2002;392-393:221-9.

25. Chiu HH, Chiang HM, Lo C-C, Chen C-Y, Chiang H-L. Constituents of volatile organic compounds of evaporating essential oil. Atmos Environ. 2009;43:5743-9.

26. De Oliveira CEL, Cremasco MA. Determination of the vapor pressure of Lippia gracilis Schum essential oil by thermogravimetric analysis. Thermochim Acta. 2014;577:1-4.

27. Brown ME, Maciejewski M, Vyazovkin S, Nomen R, Sempere J, Burnham A, Opfermann J, Strey R, Anderson HL, Kemmler A, Keuleers R, Janssens J, Desseyn HO, Li CR, Tang TB, Roduit B, Malek J, Mitsuhashi T. Computational aspects of kinetic analysis. Part A: the ICTAC kinetics project-data, methods and results. Thermochim Acta. 2000;355:125-43.

28. Vyazovkin S, Burnham AK, Criado JM, Pérez-Maqueda LA, Popescu C, Sbirrazzuoli N. ICTAC Kinetic committee recommendations for performing kinetic computations on thermal analysis data. J Therm Anal Calorim. 2011;520:1-19.

29. Vyazovkin S, Chrissafis K, Di Lorenzo ML, Koga N, Pijolat M, Roduit B, Sbirrazzuoli N, Suñol JJ. ICTAC Kinetics Committee recommendations for collecting experimental thermal analysis data for kinetic computations. Thermochim Acta. 2014;590:1-23.

30. Dweck J, Sampaio CMS. Analysis of the thermal decomposition of commercial vegetable oils in air by simultaneous TG/DTA. J Therm Anal Calorim. 2004;75(2):385-91.

31. Akahira T, Sunose T. Method of determining activation deterioration constant of electrical insulating materials. Res Rep Chiba Inst Technol (Sci Technol). 1971;16:22-31.

32. Duce C, Vecchio Ciprioti S, Ghezzi L, Ierardi V, Tinè MR. Thermal behavior study of pristine and modified halloysite nanotubes. A modern kinetic study. J Therm Anal Calorim. 2015;121(3):1011-9.

33. Sbirrazzuoli N, Vecchio S, Catalani A. Isoconversional kinetic study of alachlor and metolachlor vaporization by thermal analysis. Int J Chem Kinet. 2005;23:74-80.

34. Vecchio S, Di Rocco R, Ferragina C. Kinetic study of decomposition for Co(II)- and Ni(II)-1,10phenanthroline complexes intercalated in c-zirconium phosphate. J Therm Anal Calorim. 2009;97:805-10.

35. Vyazovkin S, Wight CA. Kinetics in solids. Annu Rev Phys Chem. 1997;48:125-49.

36. Coats AV, Redfern JP. Kinetic parameters from thermogravimetric data. Nature. 1964;201:689.

37. Sbirrazzuoli N. Determination of pre-exponential factors and of the mathematical functions $\mathrm{f}($ alpha) or G(alpha) that describe the reaction mechanism in a model-free way. Thermochim Acta. 2013;564:59-69. 
394 38. Budrugeac P, Segal E. Thermal analysis in the evaluation of thermal lifetime of solid polymeric materials. Thermochim Acta. 1992;211:131-6.

396 39. Vecchio Ciprioti S, Catauro M. Synthesis, structural and thermal behavior study of four Cacontaining silicate gel-glasses: activation energies of their dehydration and dehydroxylation processes. J Therm Anal Calorim. 2016;123(3):2091-101.

40. Catauro M, Dell'Era A, Vecchio Ciprioti S. Synthesis, structural, spectroscopic and thermoanalytical study of sol-gel derived $\mathrm{SiO} 2-\mathrm{CaO}-\mathrm{P} 2 \mathrm{O} 5$ gel and ceramic materials. Thermochim Acta. 2016;625:20-7.

41. Vecchio Ciprioti S, Catauro M, Bollino F, Tuffi R. Thermal behavior and dehydration kinetic study of SiO2/PEG hybrid gel glasses. Polim Eng Sci. 2017;. doi:10.1002/pen.24561 (in press).

42. Vecchio Ciprioti S, Bollino F, Tranquillo E, Catauro M. Synthesis, thermal behavior and 405 physico-chemical characterization of $\mathrm{ZrO} 2 / \mathrm{PEG}$ inorganic/organic hybrid materials via sol-gel technique. J Therm Anal Calorim. 2017;. doi:10.1007/s10973-017-6318-0 (in press).

43. WebBook NIST database. http://webbook.nist.gov/chemistry/. Accessed 16 May 2017. 


\section{Caption of the figures}

410 Fig. 1 Main compounds of lavender and sage essential oils extracted by microwaves, at extraction 411 time of $30 \mathrm{~min}$

Fig. 2 TG (a) and DTG (b) curves of evaporation of the EOs and components investigated under inert nitrogen atmosphere at $2 \mathrm{~K} \mathrm{~min}^{-1}$

Fig. $3 \mathrm{TG}$ (a) and $\mathrm{d} \alpha / \mathrm{d} T$ (b) versus $T$ curves of lavender at $2 \mathrm{~K} \mathrm{~min}^{-1}$

Fig. 4 Onset evaporation temperatures $\left(T_{\mathrm{on}}\right)$ extrapolated from the TG curves of the Eos and 420 components investigated at corresponding heating rate $\beta$

Fig. 5 Experimental and reconstructed $\alpha v s . T$ curves for vaporization of lavender, sage, camphor and 1,8-cineole. In order to reconstruct the curves kinetic data taken from experiments at $2 \mathrm{~K} \mathrm{~min}^{-1}$ (plots $\mathbf{a}, \mathbf{c}$, e and $\mathbf{g}$, respectively) and at $10 \mathrm{~K} \mathrm{~min}^{-1}$ (plots $\mathbf{b}, \mathbf{d}$, $\mathbf{f}$ and $\mathbf{h}$, respectively) were used

Fig. 6 Conversion dependency of activation energy of evaporation for the Eos and components investigated determined according to the integral isoconversional KAS method

Fig. 7 Conversion dependency of pre-exponential factor of evaporation for the EOs and components 430 
Fig.1

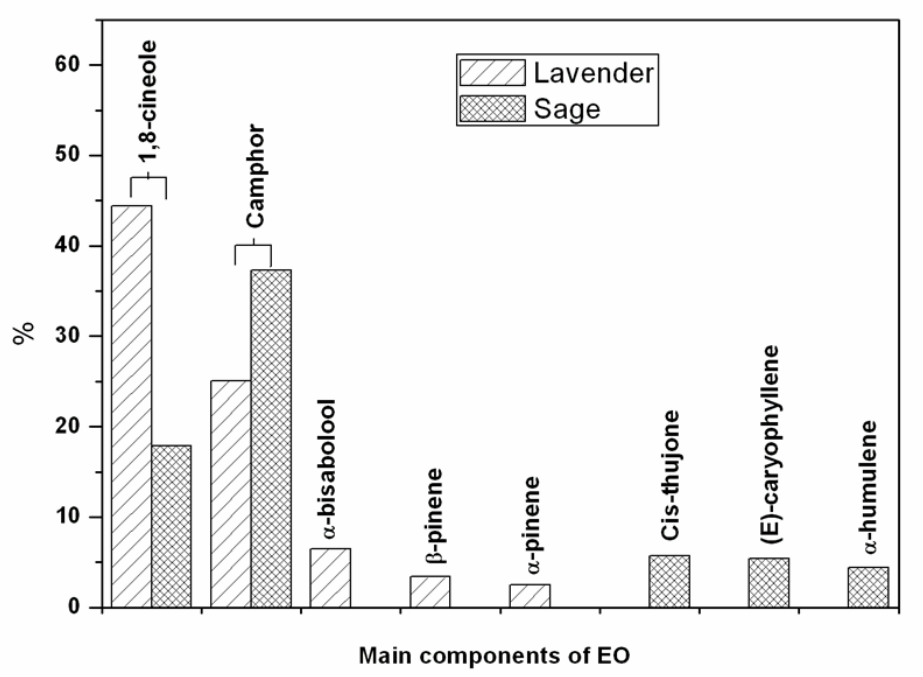

433

434 Fig. 2
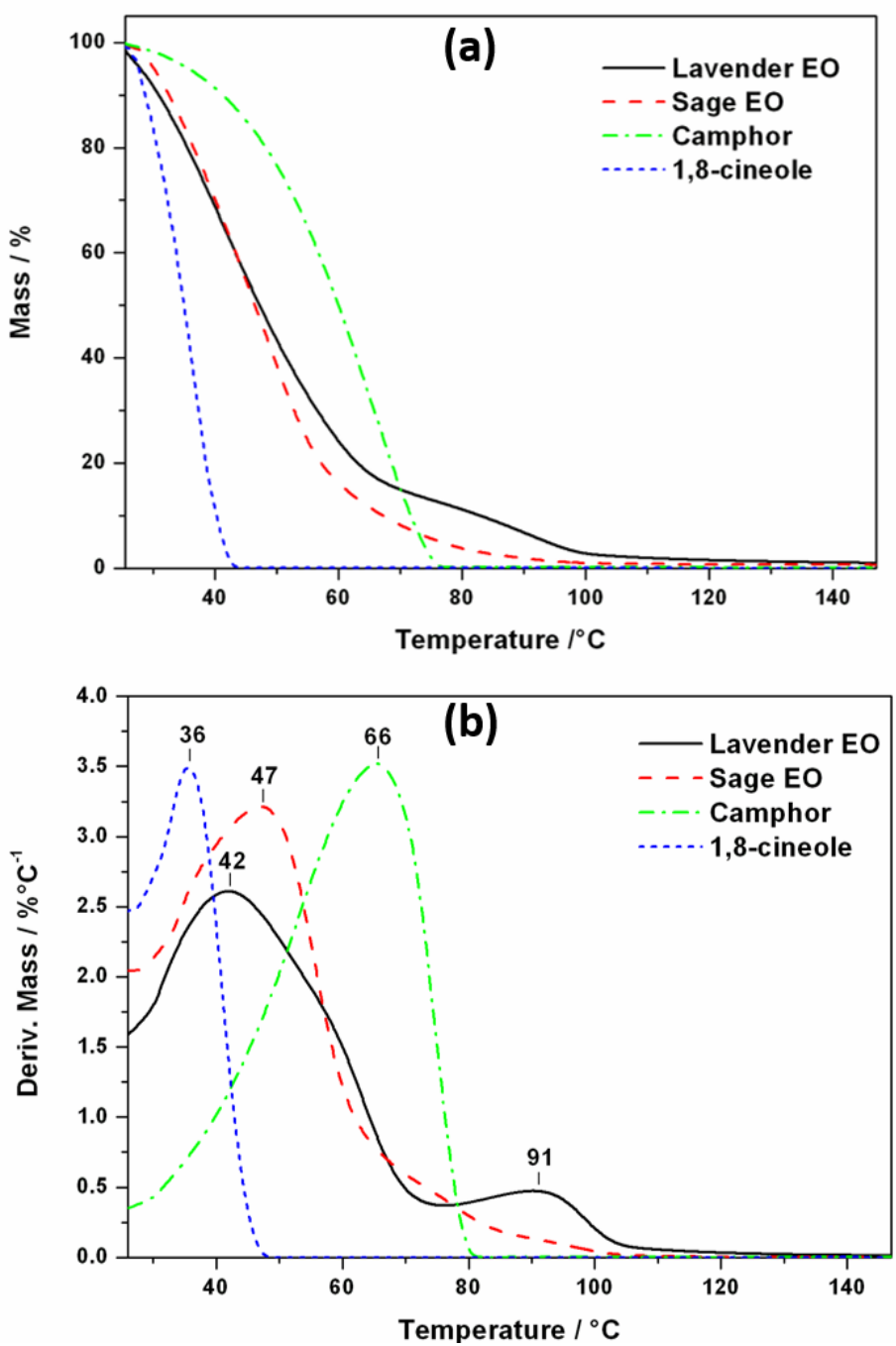
$436 \quad$ Fig. 3
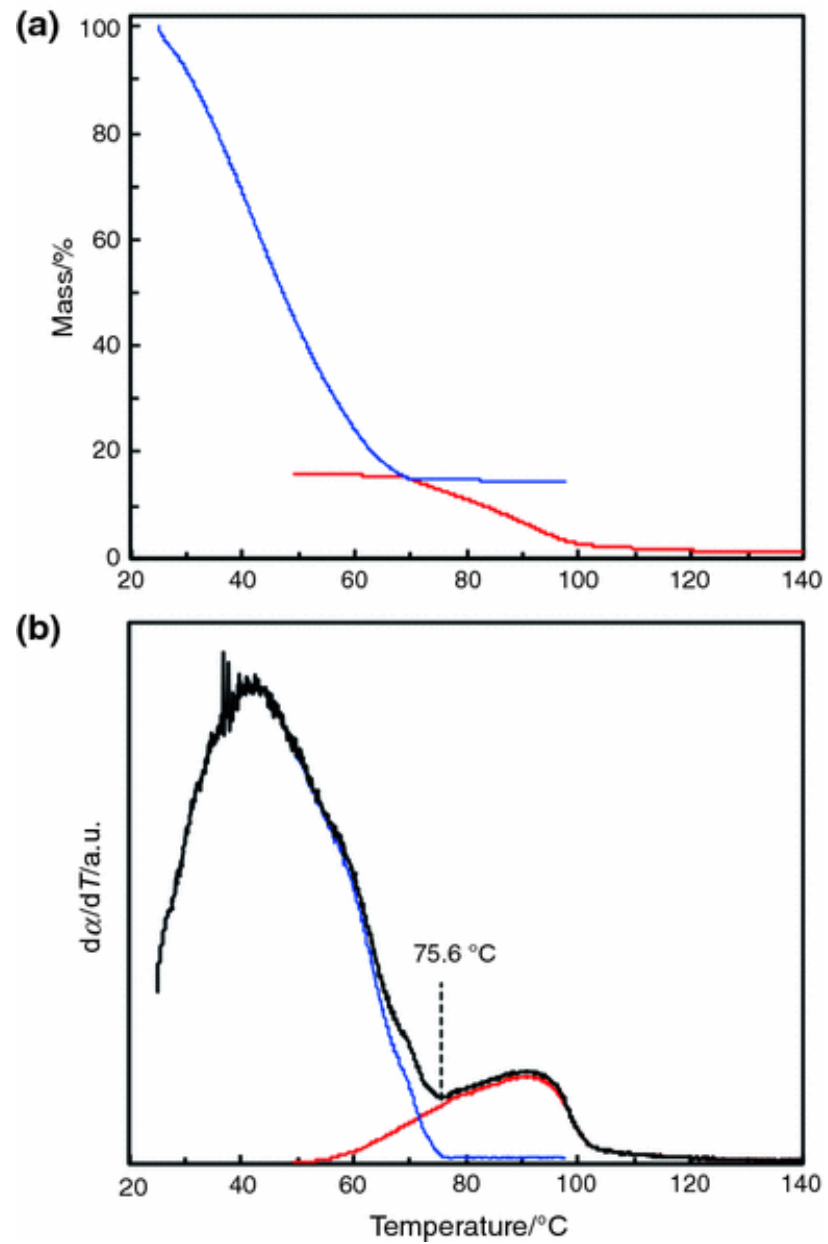
$438 \quad$ Fig. 4

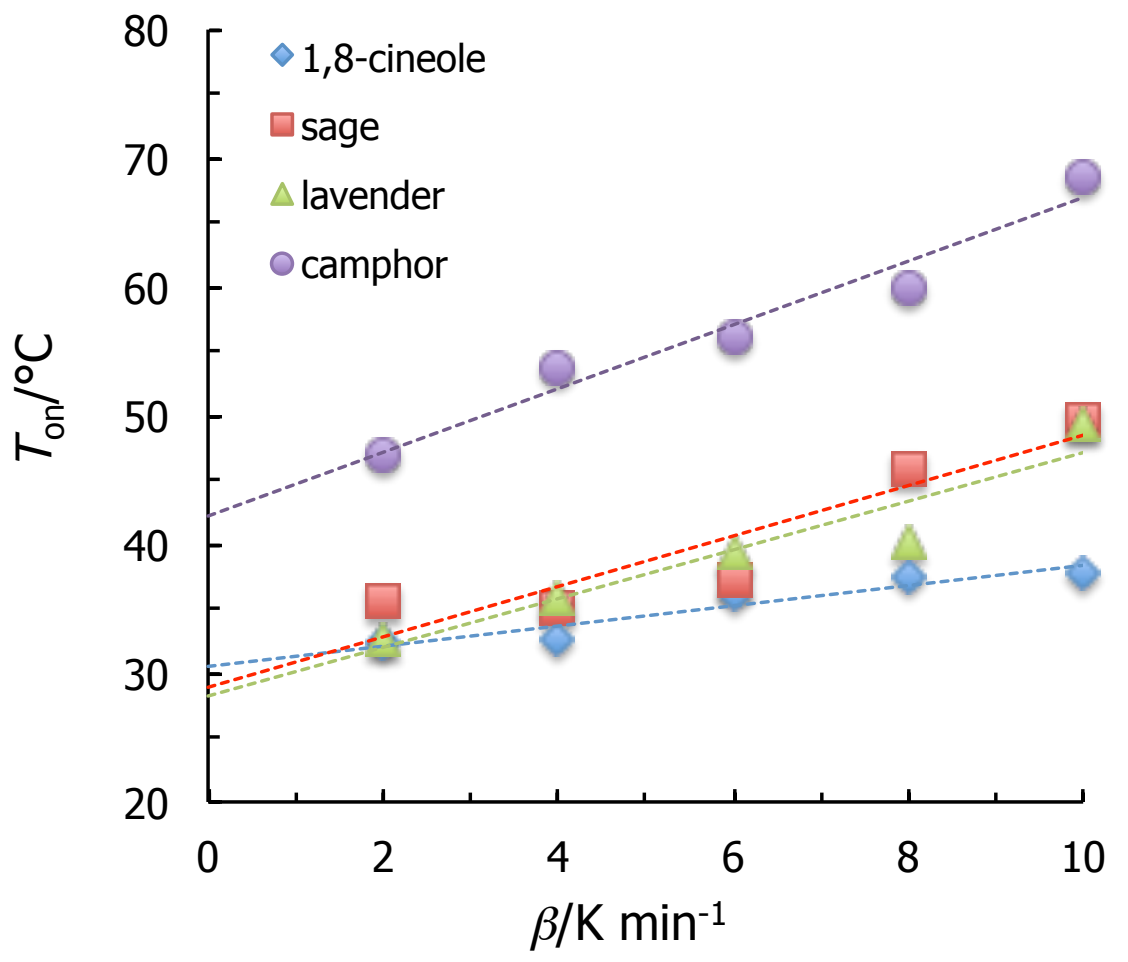


(a)

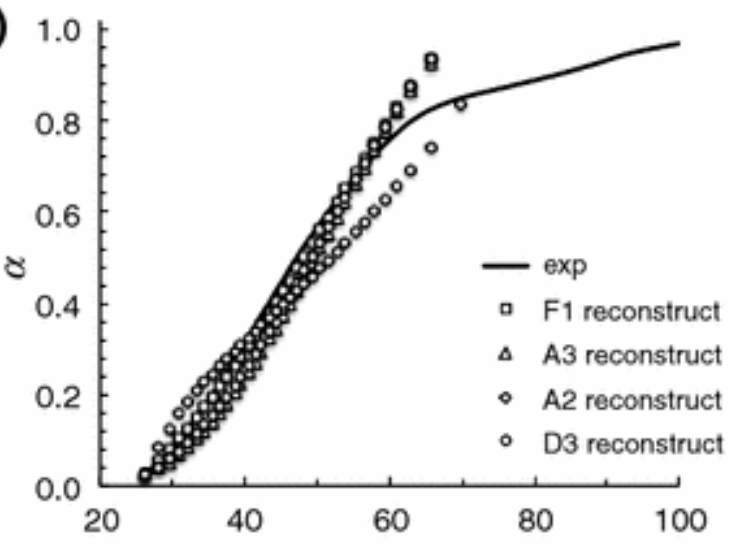

(c)

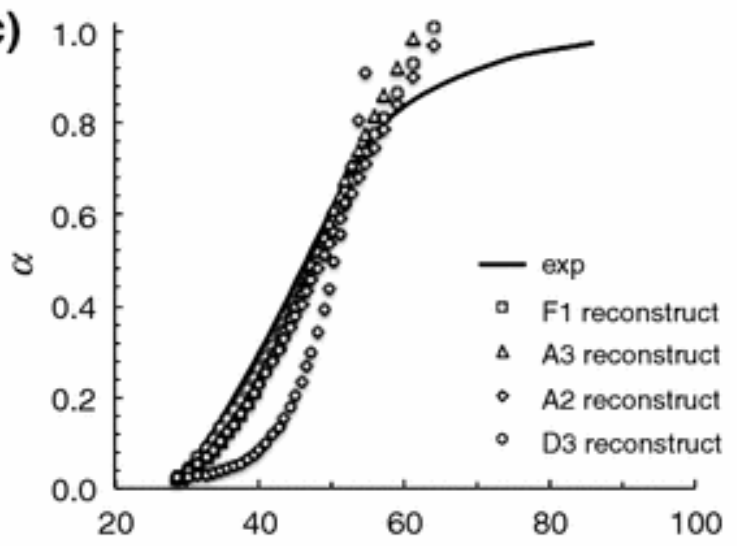

(e)

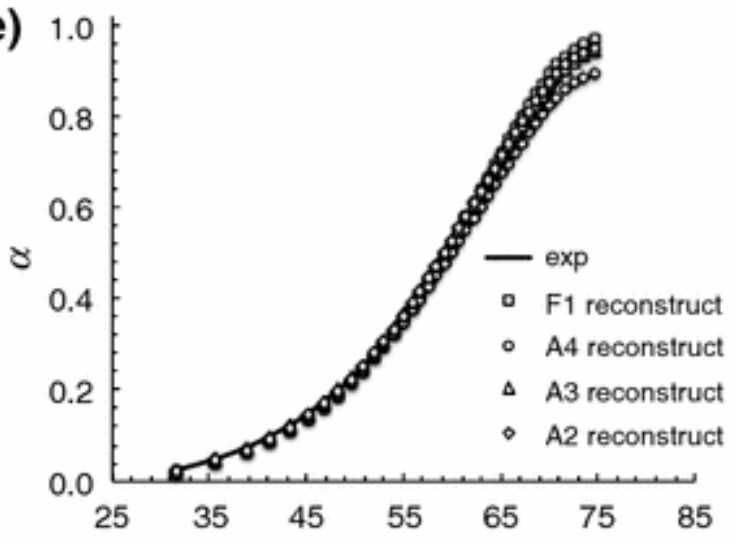

(g)

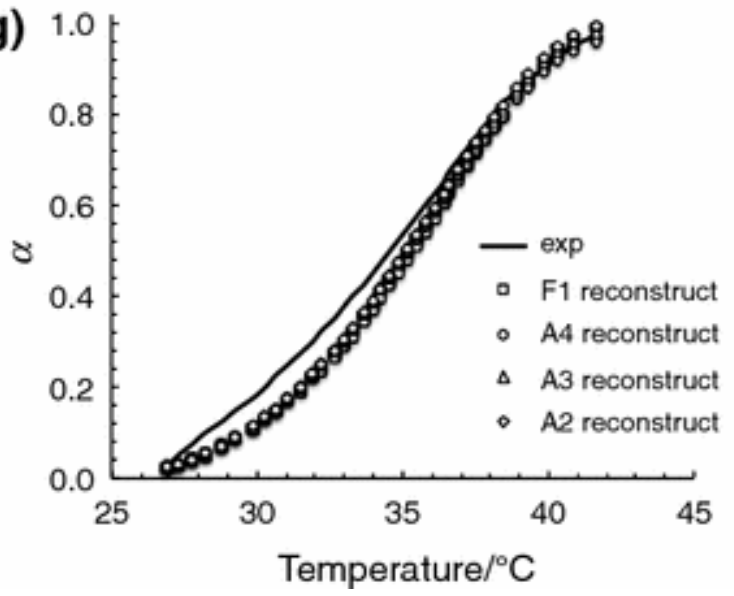

(b)

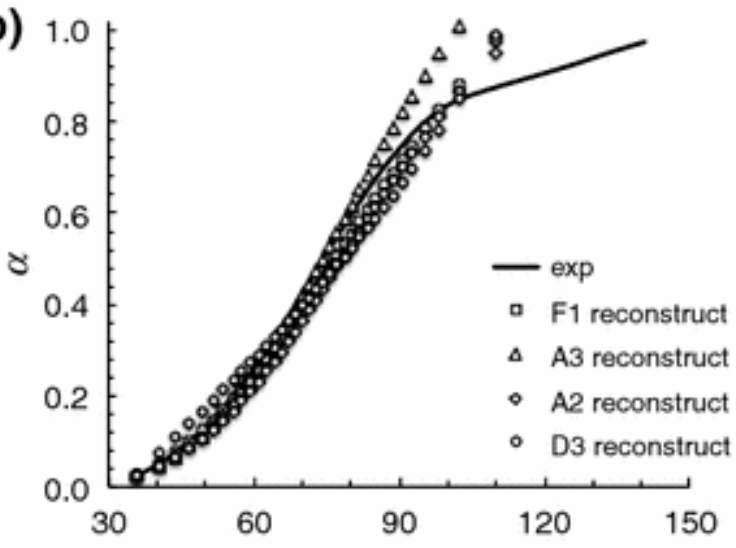

(d)

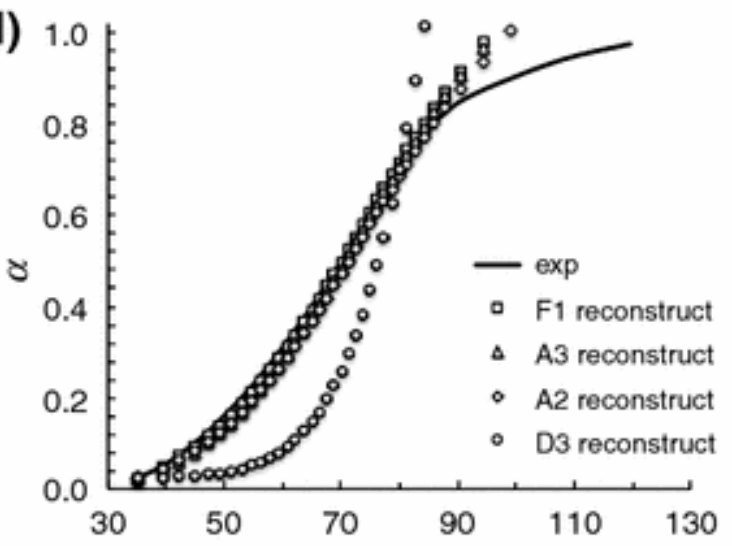

(f)

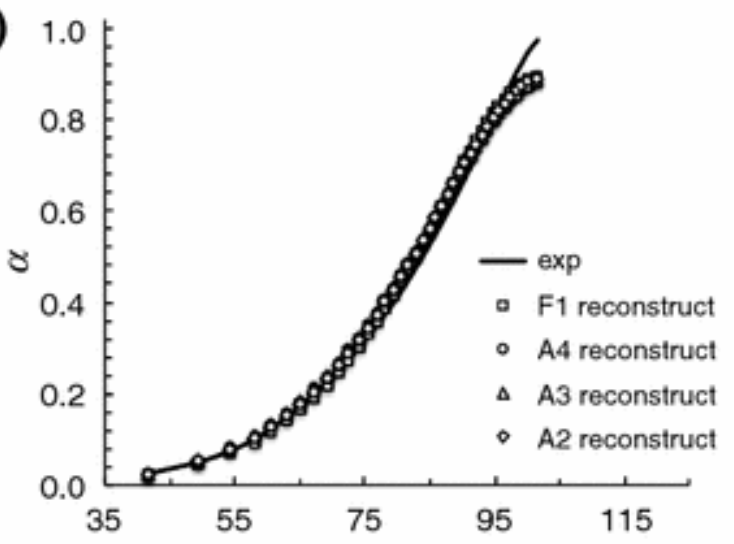

(h)

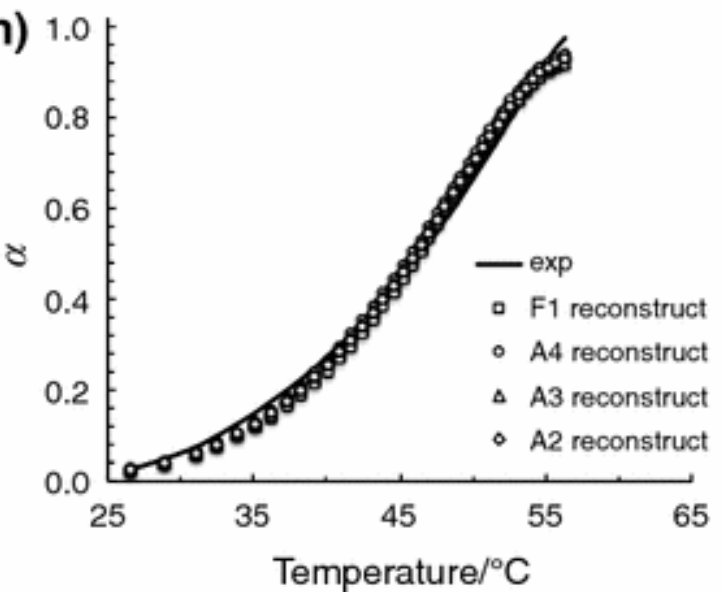


Fig. 6

443

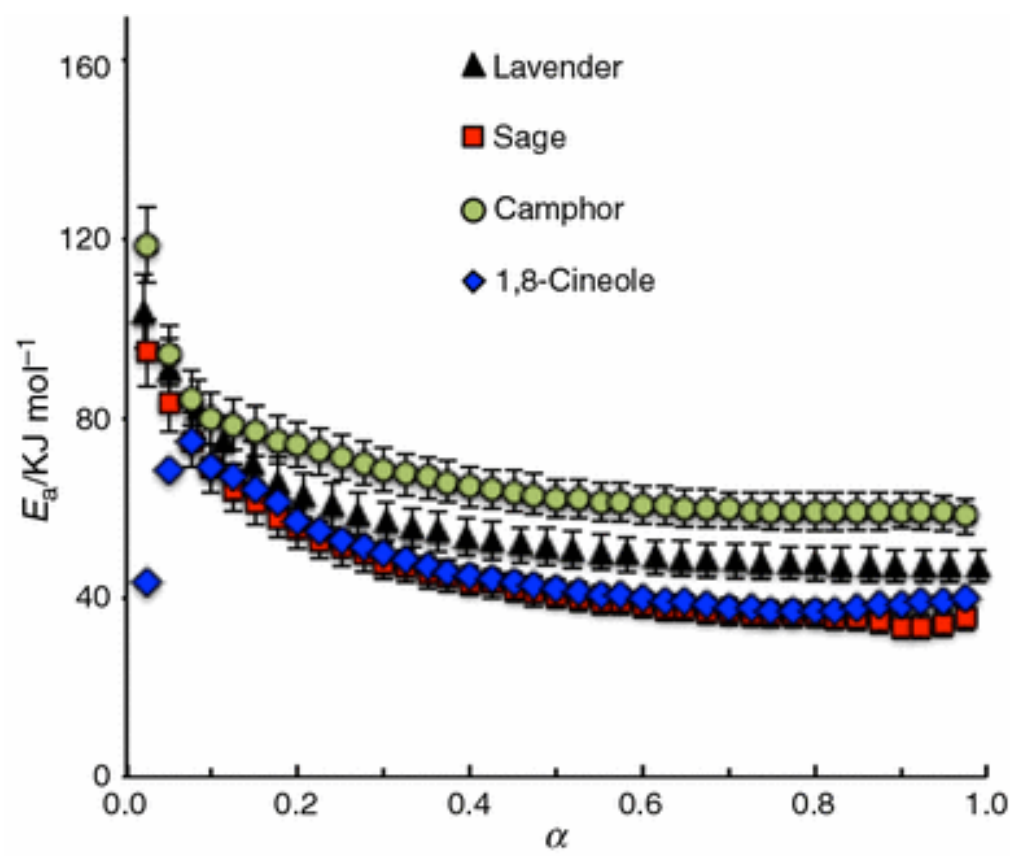

$444 \quad$ Fig. 7

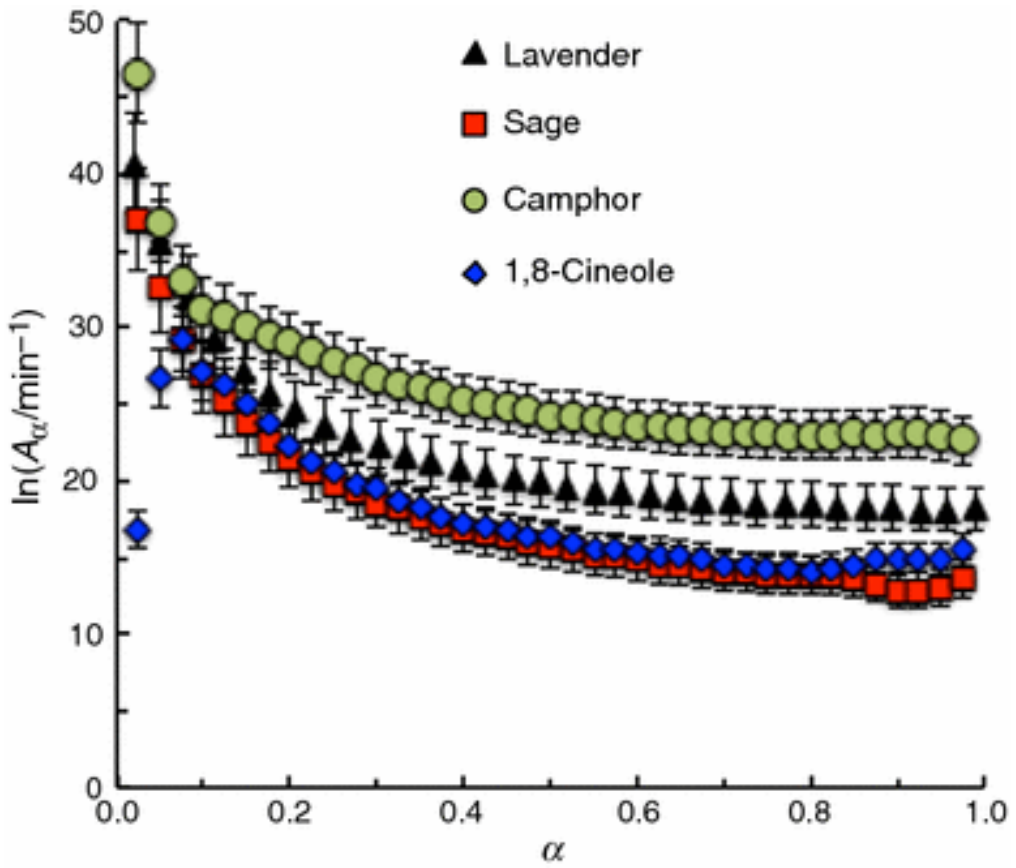


Table 1 Kinetic triplets for the most suitable mechanisms determined by the CR method according to Eq. (4) for vaporization of lavender, sage, 1,8-cineole and camphor

\begin{tabular}{|c|c|c|c|c|c|c|c|c|}
\hline Parameter & \multicolumn{4}{|c|}{ From TG experiment/2 $\mathrm{K} \mathrm{\textrm {min } ^ { - 1 }}$} & \multicolumn{4}{|c|}{ From TG experiment/10 $\mathrm{K} \mathrm{min}^{-1}$} \\
\hline \multicolumn{9}{|l|}{ Lavender } \\
\hline Best models $^{\mathrm{a}}$ & F1 & D3 & A3 & $\mathrm{A} 2$ & F1 & D3 & A3 & $\mathrm{A} 2$ \\
\hline$R^{2 \mathrm{~b}}$ & 0.8022 & 0.7640 & 0.6984 & 0.7640 & 0.8942 & 0.8635 & 0.7994 & 0.8566 \\
\hline$E_{\mathrm{a}} / \mathrm{kJ} \mathrm{mol}^{-1}$ & 47.2 & 86.7 & 12.0 & 20.8 & 40.8 & 76.6 & 9.7 & 17.5 \\
\hline$A / \mathrm{min}^{-1}$ & $5.2 \times 10^{6}$ & 0.7 & 4.5 & 170 & $9.0 \times 10^{4}$ & $1.9 \times 10^{9}$ & 1.0 & 17 \\
\hline \multicolumn{9}{|l|}{ Sage } \\
\hline Best models $^{\mathrm{a}}$ & F1 & D3 & A3 & A2 & F1 & D3 & A3 & A2 \\
\hline$R^{2 \mathrm{~b}}$ & 0.8161 & 0.7725 & 0.7609 & 0.7911 & 0.9043 & 0.8698 & 0.8548 & 0.8835 \\
\hline$E_{\mathrm{a}} / \mathrm{kJ} \mathrm{mol}^{-1}$ & 68.1 & 124 & 19.1 & 31.3 & 51.4 & 96 & 13.3 & 22.8 \\
\hline$A / \mathrm{min}^{-1}$ & $1.9 \times 10^{10}$ & $9.8 \times 10^{18}$ & 86 & $1.1 \times 10^{4}$ & $5.9 \times 10^{6}$ & $1.3 \times 10^{13}$ & 4.0 & $1.5 \times 10^{2}$ \\
\hline \multicolumn{9}{|l|}{ 1,8-Cineole } \\
\hline Best models $^{\mathrm{a}}$ & F1 & A4 & A3 & $\mathrm{A} 2$ & F1 & A4 & A3 & $\mathrm{A} 2$ \\
\hline$R^{2 \mathrm{~b}}$ & 0.8343 & 0.8256 & 0.8287 & 0.8316 & 0.9199 & 0.9196 & 0.9198 & 0.9198 \\
\hline$E_{\mathrm{a}} / \mathrm{kJ} \mathrm{mol}^{-1}$ & 250 & 49.9 & 68.3 & 105 & 114 & 24.5 & 34.4 & 54.2 \\
\hline$A / \mathrm{min}^{-1}$ & $1.2 \times 10^{36}$ & $3.6 \times 10^{7}$ & $6.2 \times 10^{10}$ & $1.5 \times 10^{17}$ & $7.7 \times 10^{17}$ & $6.4 \times 10^{2}$ & $3.4 \times 10^{4}$ & $8.5 \times 10^{7}$ \\
\hline \multicolumn{9}{|l|}{ Camphor } \\
\hline Best models ${ }^{\mathrm{a}}$ & F1 & A4 & $\mathrm{A} 3$ & A2 & $\mathrm{F} 1$ & A4 & A3 & $\mathrm{A} 2$ \\
\hline$R^{2 \mathrm{~b}}$ & 0.9960 & 0.8371 & 0.8305 & 0.8388 & 0.9917 & 0.9319 & 0.9282 & 0.9250 \\
\hline$E_{\mathrm{a}} / \mathrm{kJ} \mathrm{mol}^{-1}$ & 88 & 17.9 & 25.7 & 41.2 & 70.9 & 13.4 & 19.8 & 32.6 \\
\hline$A / \mathrm{min}^{-1}$ & $9.5 \times 10^{12}$ & 28 & $6.4 \times 10^{2}$ & $2.6 \times 10^{5}$ & $2.6 \times 10^{9}$ & 2.9 & 33 & $3.6 \times 10^{3}$ \\
\hline
\end{tabular}

Relative standard deviations (RSD) associated with $E_{\mathrm{a}}$ and $A$ values were always lower than $6 \%$

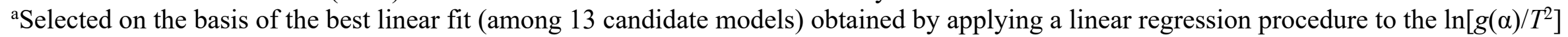
versus $1 / T$ data according to Eq. (4)

${ }^{b}$ Value referred to the best four linear fits obtained by plotting $\ln \left[g(\alpha) / T^{2}\right]$ versus $1 / T$ according to Eq. (4) 
Table 2 Regression parameter values related to Eq. (6) at each TG experiment at a given value of $\beta$

\begin{tabular}{|c|c|c|c|c|c|c|}
\hline \multirow[t]{2}{*}{ Parameter } & \multicolumn{5}{|c|}{ Data obtained at a given value of $\beta$} & \multirow{2}{*}{$\begin{array}{l}\text { Averages, }\langle a\rangle \text { and } \\
\langle-b\rangle\end{array}$} \\
\hline & $2 \mathrm{~K} \mathrm{~min}^{-1}$ & $4 \mathrm{~K} \mathrm{~min}^{-1}$ & $6 \mathrm{~K} \mathrm{~min}^{-1}$ & $8 \mathrm{~K} \mathrm{~min}^{-1}$ & $10 \mathrm{~K} \mathrm{~min}^{-1}$ & \\
\hline$a$ & 0.396 & 0.395 & 0.397 & 0.395 & 0.398 & 0.396 \\
\hline$-b$ & 3.5 & 3.4 & 3.4 & 3.5 & 3.5 & 3.5 \\
\hline $\mathrm{SD}(a)^{\mathrm{a}}$ & 0.006 & 0.009 & 0.007 & 0.010 & 0.012 & \\
\hline $\mathrm{SD}(b)^{\mathrm{b}}$ & 0.5 & 0.6 & 0.5 & 0.6 & 0.6 & \\
\hline $\mathrm{SD}(y: x)^{\mathrm{c}}$ & 1.3032 & 1.3306 & 1.3131 & 1.3997 & 1.4347 & \\
\hline$R^{2}$ & 0.9964 & 0.9910 & 0.9955 & 0.9887 & 0.9859 & \\
\hline$F$ obs. value & 3832 & 2845 & 3451 & 2556 & 2015 & \\
\hline
\end{tabular}

454 aStandard deviation of the slope

455 bStandard deviation of the intercept

456 'Standard deviation of the estimate of $y\left(\ln A_{\mathrm{i}}\right)$ by the regression line through Eq. (6) 